\title{
A conceptual design study of pool-type sodium-cooled fast reactor with enhanced anti-seismic capability
}

\author{
Shigenobu KUBO*, Yoshitaka CHIKAZAWA*, Hiroyuki OHSHIMA*, Masato UCHITA**, \\ Takayuki MIYAGAWA**, Masao ETO***, Tetsuji SUZUNO***, Ichiyo MATOBA***, \\ Junji ENDO***, Osamu WATANABE*** and Koichi HIGURASHI*** \\ *Japan Atomic Energy Agency (JAEA) \\ 4002 Narita-Cho, Oarai, Ibaraki 311-1393, Japan \\ E-mail: kubo.shigenobu@jaea.go.jp \\ **The Japan Atomic Power Company (JAPC) \\ 5-2-1 Ueno, Taito-ku, Tokyo 110-0005, Japan \\ *** Mitsubishi FBR Systems, Inc. (MFBR) \\ 2-34-17 Jingumae, Shibuya-ku, Tokyo 150-0001, Japan
}

Received: 9 October 2019; Revised: 15 December 2019; Accepted: 2 March 2020

\begin{abstract}
The authors are developing the design concept of the pool-type sodium-cooled fast reactor (SFR) that addresses Japan's specific siting conditions such as earthquakes and meets safety design criteria (SDC) and safety design guidelines (SDG) for Generation IV SFRs. The development of this concept will broaden not only options for reactor types in Japan but also the range and depth of international cooperation. A design concept of 1,500 MWt (650 MWe) class pool-type SFR was thought up by applying design technology obtained from the design of advanced loop-type SFR, named JSFR, equipped with safety measures that reflect results from the feasibility study on commercialized fast reactor cycle systems and fast reactor cycle technology development, improved maintainability and repairability, and lessons learned from the Fukushima Daiichi Nuclear Power Plants accident. The design concepts of a reactor vessel (RV) and its internal structures have been investigated whether they could withstand severe seismic conditions in Japan and thermal loads. The design adopted enhanced RV support structure, enhanced conical-shaped core support structure, a thickened knuckle part of the RV, and a flat plenum separator with ribs. A three-dimensional steady-state thermal hydraulic analysis of the RV revealed that the temperature difference of the upper and lower surfaces of the flat plenum separator could be effectively reduced by installing layers of thermal insulation plates. The authors have also conducted a transient analysis of loss of flow type anticipated transients without scram events to evaluate the feasibility of a self-actuated shutdown system. Moreover, the configuration of the decay heat removal system has been investigated considering sufficient utilization of natural circulation capability of sodium coolant, heat removal capacity of each cooling system, conformance with design requirements, and recommendations of SDC and SDG such as diversity and redundancy of components.
\end{abstract}

Keyword : Pool-type sodium-cooled fast reactor, Anti-seismic design, Reactor structure,

Three-dimensional thermal hydraulic analysis, Safety design criteria, Safety design guidelines

\section{Introduction}

From 1999 to 2006, the Feasibility Study on commercialized fast reactor cycle systems (FS) in Japan was conducted to develop innovative fast reactor design concepts that would meet design targets of future sustainable commercial reactors by exploring a broad range of combinations of various coolants, e.g., liquid metal, gas and water, and fuels, e.g., oxide, metal and nitride (Kotake et al., 2005). As a result, a loop-type oxide fuel sodium-cooled fast reactor named JSFR was selected as the most promising design concept for commercialization. Later, the Fast Reactor Cycle Technology Development $(\mathrm{FaCT})$ project made progress on the conceptual design of the JSFR and the 
Kubo, Chikazawa, Ohshima, Uchita, Miyagawa, Eto, Suzuno, Matoba, Endo, Watanabe and Higurashi, Mechanical Engineering Journal, Vol.7, No.3 (2020)

innovative technologies used in the JSFR (Hayafune et al., 2011). Although the project was suspended in 2011, the design of the JSFR has been progressed by improving maintainability and repairability (Isono et al., 2014) and safety measures based on lessons learned from the Fukushima Daiichi Nuclear Power Plants accident (Kamide et al., 2015). In the FS, pool-type SFR design concepts were studied as other feasible concepts. One of the reasons to choose the loop-type is that it potentially allows the plant to further reduce its plant materials in the future by eliminating its secondary sodium circuits.

To promote fast reactor development, international cooperation is essential. JAEA, MHI, MFBR have been engaged in international collaboration on sodium-cooled fast reactors (SFRs) such as ASTRID (pool-type) collaboration with France (Varaine et al., 2018). Pool-type design is the mainstream of SFR globally. Given this situation, it is important to study pool-type design as well.

\section{Design concept of a pool-type SFR}

As a demonstration reactor toward future commercialization of SFR, the pool-type design concept in this study took the possibility of its output power being increased into account. In addition, design parameters such as the number of cooling circuits and output power should be selected flexibly as needed because target electric power for commercial SFRs will depend on circumstances, for example, energy markets, political decisions, and regulations in the future. Table 1 lists the main parameters of the design concept. These are tentative, and the set of decay heat removal systems (DHRSs) is also one of the options aiming at complying with the safety design criteria (SDC) and safety design guidelines (SDG) for SFRs (GIF SDC-TF, 2016, 2017). Also, this concept adopted a horizontal seismic isolation system in the reactor building.

Table 1 Main technical parameters.

\begin{tabular}{|l|l|}
\hline \multicolumn{1}{|c|}{ Item } & \multicolumn{1}{c|}{ Value or System } \\
\hline Electrical output & $650 \mathrm{MWe}$ \\
\hline Core inlet/outlet coolant temperature & $550 / 400$ deg. C \\
\hline Reactor shutdown systems & $\begin{array}{l}2 \text { active shutdown systems with } \\
\text { Self-Actuated Shutdown System (SASS) }\end{array}$ \\
\hline Primary pumps & 3 mechanical pumps \\
\hline Intermediate heat exchangers (IHXs) & 4 IHXs (Straight tube containing secondary coolant inside) \\
\hline Secondary pumps & 4 mechanical pumps \\
\hline Power conversion & 4 steam generators, 1 water-steam turbine \\
\hline Decay heat removal systems (DHRSs) & 1 immersed direct reactor auxiliary cooling system (DRACS) \\
& 4 Intermediate reactor auxiliary cooling system (IRACS) \\
& 1 penetrated-DRACS \\
\hline Spent fuel storage & Ex-vessel storage tank \\
\hline Seismic isolation system & Horizontal seismic isolation system on the building base \\
\hline
\end{tabular}

\section{Study of reactor structure}

This study examined the design concept of the reactor structure of the 650 MWe pool-type SFR and evaluated its capability to withstand earthquakes and thermal loads during its plant lifetime.

\subsection{Structural design and seismic evaluation}

An SFR is operated under low pressure conditions at high temperatures and has thin-walled structures (e.g., a reactor vessel (RV)) to reduce thermal stress. On the other hand, the thin walls are a drawback against seismic loads. To enhance its seismic capacity, the wall of the RV should be thickened but should be kept as thin as possible. 


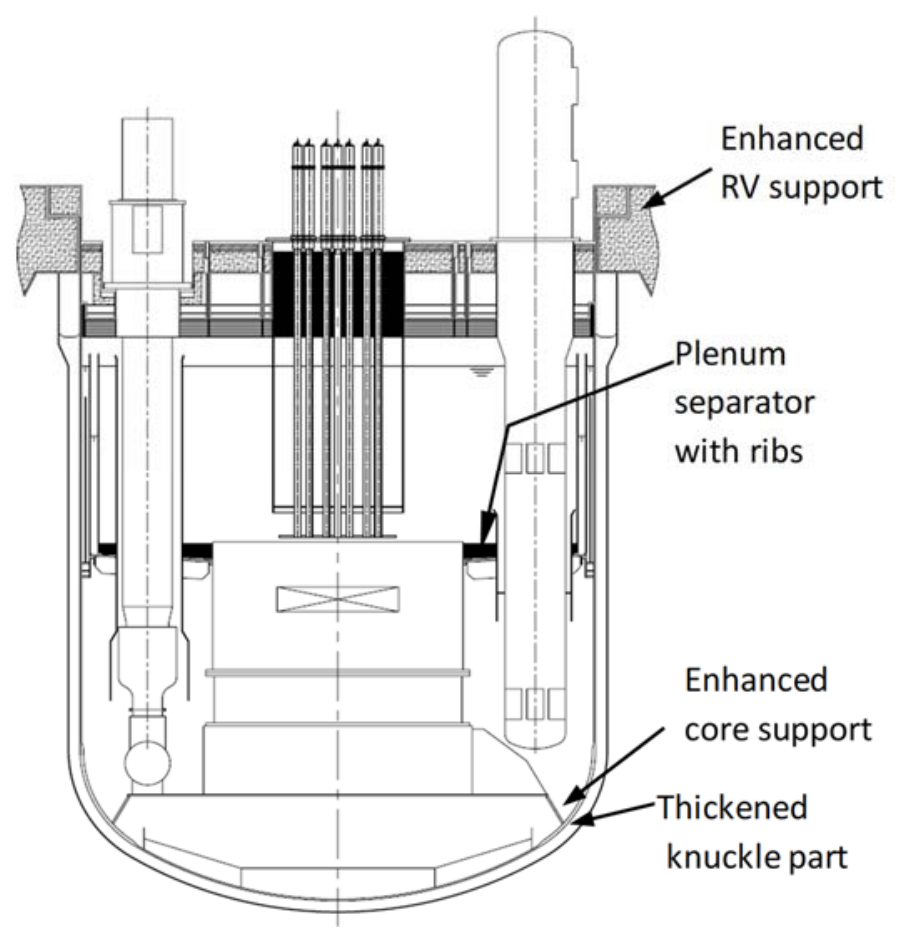

Fig. 1 Concept of reactor structure.

Figure 1 shows the design concept of the reactor structure with enhanced anti-seismic capability. In terms of the buckling strength, vertical response to seismic loads should be decreased. Therefore, its vertical natural frequency should be higher, in other words, its vertical natural period should be lower than the peak of vertical floor response spectra (FRS) in order to avoid responding to the peak acceleration. This design concept features enhanced RV support structure, enhanced conical-shaped core support structure, a thickened knuckle part of the RV, and a flat plenum separator with ribs. In order to minimize the elastic deformation of the RV flange structure by the earthquake, the thickness of the RV flange was increased. Also, the thickened knuckle part could minimize the elastic deformation of the vessel bottom. The flat-shaped plate plenum separator, which was reinforced by attaching ribs radially on the undersurface, was introduced instead of the conical-shaped one. The connecting part between the core support and RV was moved outward to increase the stiffness of the core support structure. Those structures can ensure the stiffness of the reactor structure and decrease the vertical response. The thickness of the cylindrical part of the RV is increased as necessary.

This study used typical seismic load conditions of Japan as input. Fig. 2 shows horizontal ground motion spectra on a free rock surface assumed as the design basis in this study. Two spectra A and B were used to examine the sensitivity to the structural design (Uchita et al., 2018). Vertical ground motions were assumed as two-thirds of horizontal ground motions. By using a simple spring-mass model, the seismic response analysis of the reactor building was carried out. The reactor building had the horizontal seismic isolation on the building base, and the system consisted of laminated rubber bearings and oil dampers (Fukasawa et al., 2018). To prevent buckling, the authors set the thickness of the RV to meet the criteria developed by Matsuura et al., based on experiments (1) (Matsuura et al., 1993).

$$
\left\{\frac{Q}{Q_{a l}}\right\}^{5}+\left\{\frac{M}{M_{a l}}+\frac{F}{F_{a l}}\right\}^{5}<1
$$

$Q, Q_{a l}:$ Transverse shear load and transverse shear buckling limit load $M, M_{a l}$ : Applied bending moment and limit bending buckling moment $F, F_{a l}:$ Applied axial force and axial buckling limit force

Table 2 shows the results under several output power conditions, which have appropriate margins. It was found that large scale plants (1,000 MWe, 1,500 MWe) with larger diameter RVs and more components such as primary pumps and IHXs required $60 \mathrm{~mm}$ or thicker walls for their cylindrical parts. Therefore, it is important to confirm the feasibility 
Kubo, Chikazawa, Ohshima, Uchita, Miyagawa, Eto, Suzuno, Matoba, Endo, Watanabe and Higurashi,

Mechanical Engineering Journal, Vol.7, No.3 (2020)

of enlarged RVs in terms of the structural integrity against thermal stress and manufacturability. To ensure the feasibility of the enlarged RV, countermeasures may be needed, e.g., reduction in the RV diameter increase, reduction of seismic loads, relaxation of thermal transients. An optimum countermeasure is to introduce a three-dimensional seismic isolation system (Miyagawa et al., 2017). The seismic isolation of the system in the horizontal direction is the same as the horizontal seismic isolation system. And the system has a stack of disc springs and the vertical oil dampers in order to reduce the seismic response in the vertical direction. The previous study (Fukasawa et al., 2019) shows that the vertical seismic response of RV is approx. $40 \%$ of the case of the horizontal seismic isolation system around $10 \mathrm{~Hz}$ vertical frequency. If the system is adopted, the required thickness of the walls of the enlarged $\mathrm{RV}$ will be reduced to approx. $40 \mathrm{~mm}$, even for the 1,500 MWe under the seismic condition of spectrum A.

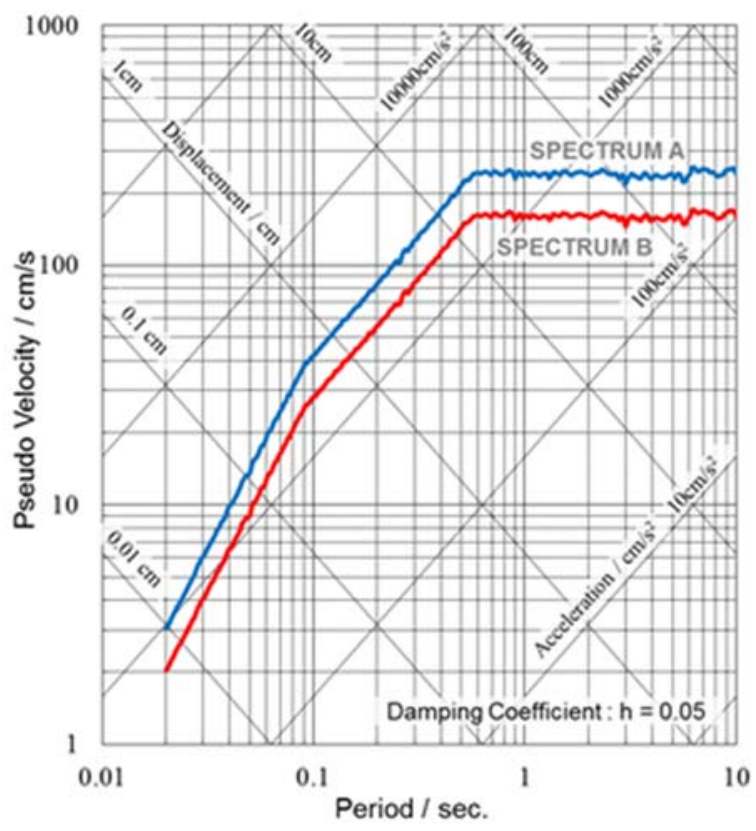

Fig. 2 Horizontal ground motion spectra.

Table 2 Necessary vessel thickness.

\begin{tabular}{|c|l||c|c|c|}
\hline \multirow{2}{*}{ SPECTRUM } & PART & $\begin{array}{c}600 \mathrm{MWe} \\
(15.9 \mathrm{~m})\end{array}$ & $\begin{array}{c}1000 \mathrm{MWe} \\
(17.2 \mathrm{~m})\end{array}$ & $\begin{array}{c}1500 \mathrm{MWe} \\
(19.4 \mathrm{~m})\end{array}$ \\
\hline \multirow{2}{*}{$\mathrm{B}$} & CYLINDER & 50 & 55 & 60 \\
\cline { 2 - 5 } & KNUCKLE & 100 & 110 & 120 \\
\hline \multirow{2}{*}{$\mathrm{A}$} & CYLINDER & 55 & 60 & 65 \\
\cline { 2 - 5 } & KNUCKLE & 100 & 120 & 130 \\
\hline
\end{tabular}

*: RV diameter

(mm)

The plenum separator, one of the internal structures of the RV, is also needed to ensure the seismic capability. Design concepts of the plenum separator in some countries are shown in Table 3 schematically. This study adopted a single plate type separator, just as shown in the sketch of ASTRID (Table 3), because of its advantageous simple configuration. On the other hand, the single plate type has a disadvantage in that it will have severe temperature transients on both sides of the plate-accumulative creep fatigue damage to the steel material. Then, the authors adopted a flat-shaped single plate plenum separator and attached reinforcing ribs radially on the undersurface to ensure the seismic capability. In addition, layers of steel plates were installed on the hot plenum side as thermal insulation. Findings of a modal spectral analysis performed to evaluate the stiffness of the plenum separator showed that the natural frequency was $16 \mathrm{~Hz}(0.06 \mathrm{~s})$, and vertical seismic loads to the plenum separator were adequately suppressed (Fig. 3). This is because its natural frequency was higher, in other words, its natural period was lower, enough than the peak acceleration range. 
Kubo, Chikazawa, Ohshima, Uchita, Miyagawa, Eto, Suzuno, Matoba, Endo, Watanabe and Higurashi, Mechanical Engineering Journal, Vol.7, No.3 (2020)

Table 3 Various design concepts of plenum separators (IAEA, 2006).

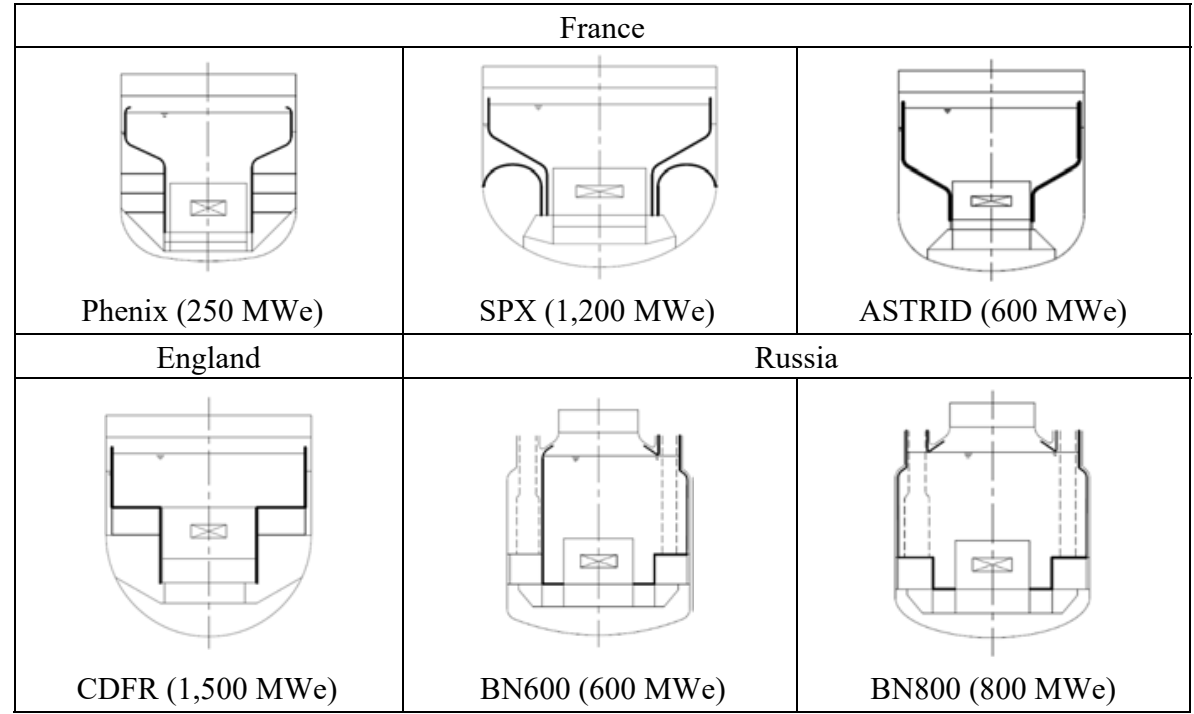

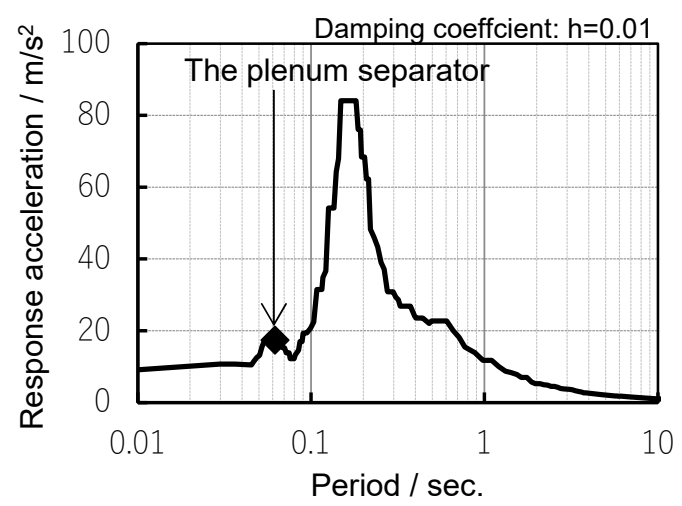

Fig. 3 Vertical FRS at the RV support level.

\subsection{Thermal hydraulic evaluation}

This study conducted a three-dimensional steady-state thermal hydraulic analysis to confirm the resistance of the plenum separator against a thermal load under a rated operating condition. As shown in Fig. 4, the plenum separator has 13 thermal insulation plates on its upper surface to reduce a large temperature difference on its upper and lower surfaces. This analysis focused on the effectiveness of the thermal insulation plates.

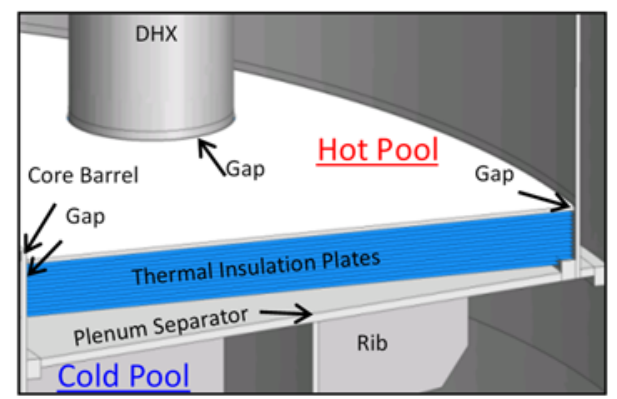

Fig. 4 Thermal insulation plates.

Figure 5 depicts a quadrant model of the RV, including the core, the IHX, the decay heat exchanger (DHX) and the pump. The thermal insulation plates and gaps were simulated in detail because they are considered to have impacts on the upper surface temperature. The ribs were also modeled because they would affect the lower surface temperature. The number of meshes in the computation was 3.7 million. Using STAR-CCM+ Ver.11, the authors applied realizable 
$\mathrm{k}-\varepsilon$ as a turbulent model and a second-order up-wind differencing scheme for advection term in space. Boundary conditions given in this analysis were heat generation in the core, heat removal in the IHX, and a primary flowrate.

Figure 5 shows the temperature distribution in the RV, and Fig. 6 shows temperature distribution around the thermal insulation plates at a representative cross section, in which internal structures such as IHX and pump are not located. The authors observed the temperature reduction effect of the thermal insulation plates on the upper surface, especially in the lower half region. The temperature difference of the upper and lower surfaces of the plenum separator became approx. $50^{\circ} \mathrm{C}$, which was $60^{\circ} \mathrm{C}$ lower than that of the conical-shaped structure without the thermal insulation plates. Its horizontal shape and the thermal insulation plates prevented the hot coolant from colliding directly to the upper surface of plenum separator in comparison with the conical-shaped structure (Fig. 7). On the other hand, the temperature reduction was not enough in the higher half region.

In the hot pool side of the plenum separator, the hot coolant flowed into the gaps in between the thermal insulation plates, causing insufficient heat shielding (Fig. 8).

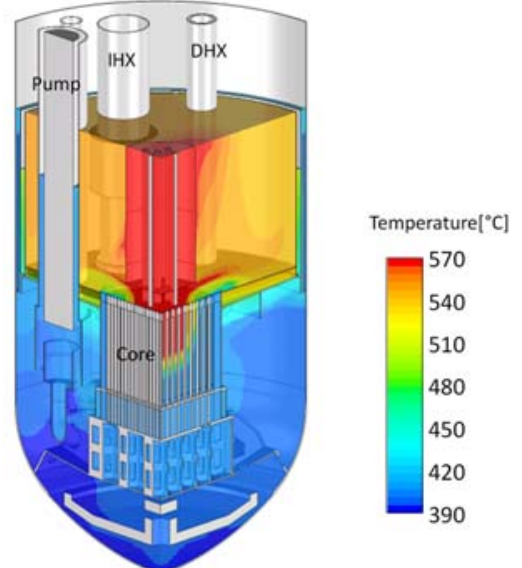

Fig. 5 Temperature distribution in the reactor vessel.
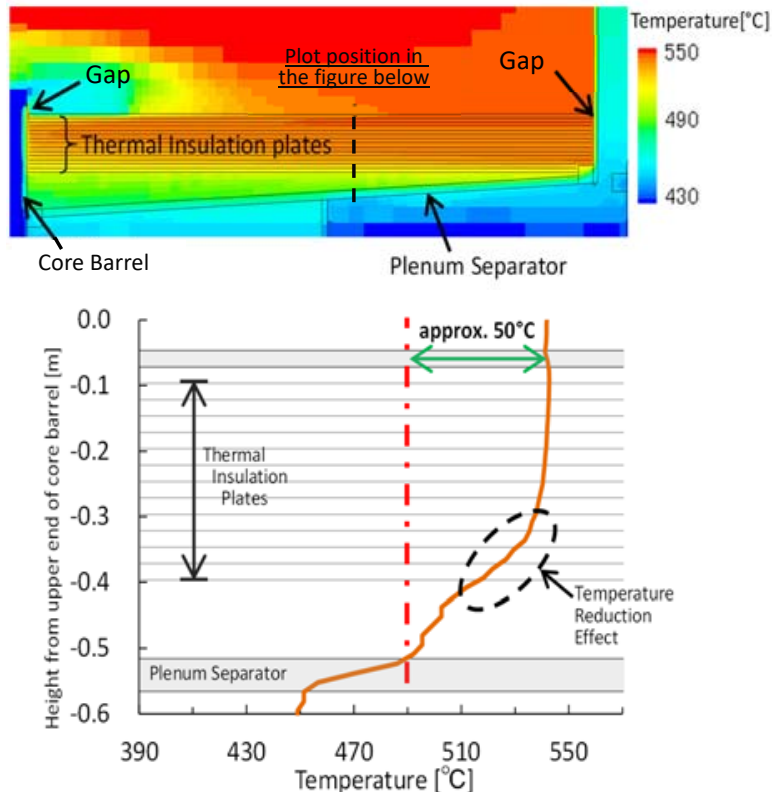

Fig. 6 Temperature distribution around the thermal insulation plates.

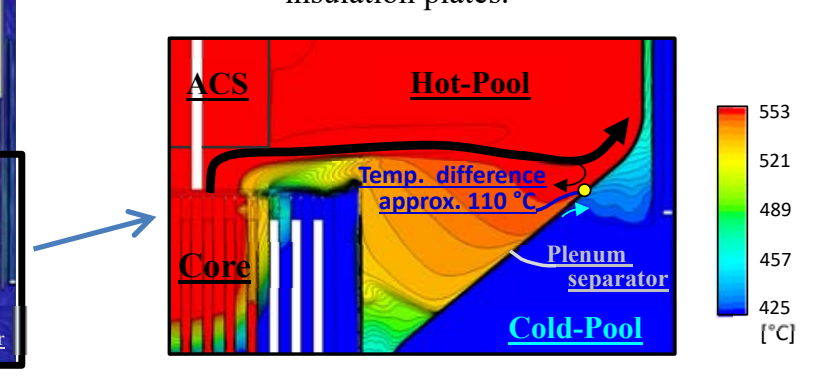

Temperature

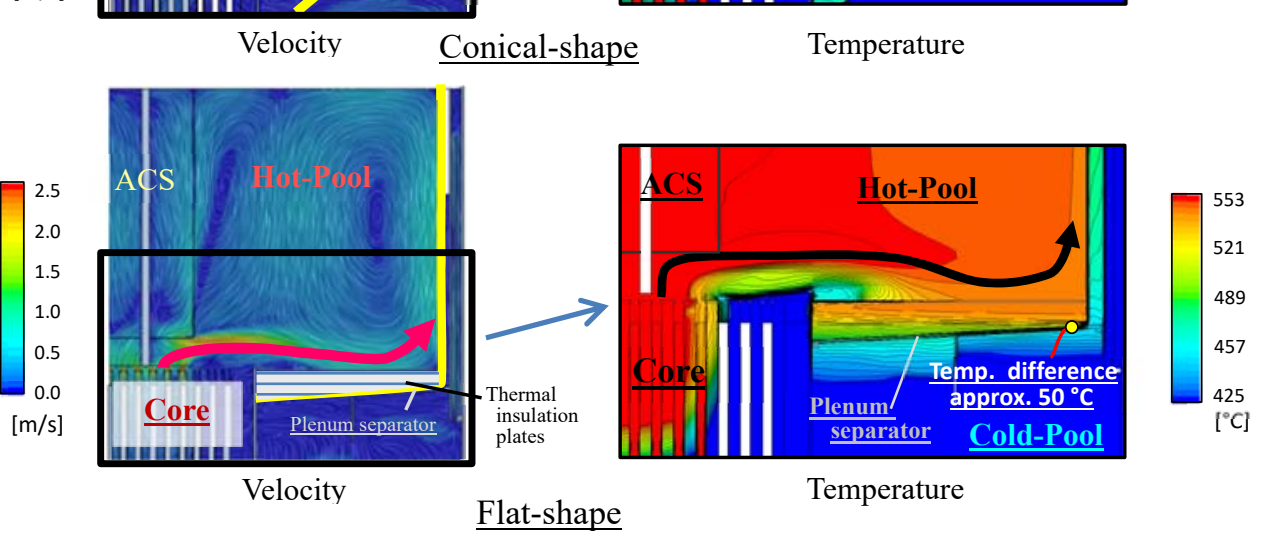

Fig. 7 Temperature and Velocity distribution in the hot pool. 
In the cold pool side of the plenum separator, a low-temperature region was locally formed on its lower surface (Fig. 9). Cold coolant from the IHX flowed toward the pump, collided with the lower surface of the plenum separator, and stayed there as stagnant regions because of the surrounding ribs, causing an increase in the temperature difference.

It was concluded that countermeasures would be necessary to restrict the flow of hot coolant into the gaps and to prevent the occurrence of stagnant regions around the ribs. The authors performed an additional analysis to confirm the effectiveness of the two measures. As a countermeasure to restrict the hot coolant flow into the gaps, the installation of porous media into the gaps was considered (Fig. 10). The material of the porous media was assumed as packed metal fibers that can deform according to the thermal expansion of thermal insulation plates. Pressure loss coefficient and porosity corresponding to sample metal fivers were given to the porous media. The measure to prevent the occurrence of stagnant regions around the ribs was also taken in the analysis. As shown in Fig. 11, flow holes were made in the ribs, which were also modeled by porous media to simulate the flow through ribs. The porosity of $10 \%$ and the pressure loss coefficient corresponding to $\phi 100 \mathrm{~mm}$ flow holes were applied to the porous media. In the hot pool side of the plenum separator, the hot coolant into thermal insulation plates was suppressed (Fig. 12). In the cold pool side of the

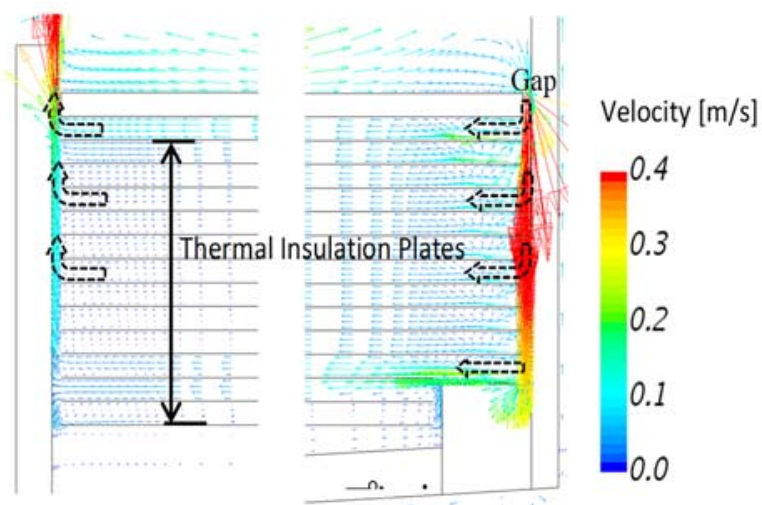

Fig. 8 Velocity distribution in the thermal insulation plates.

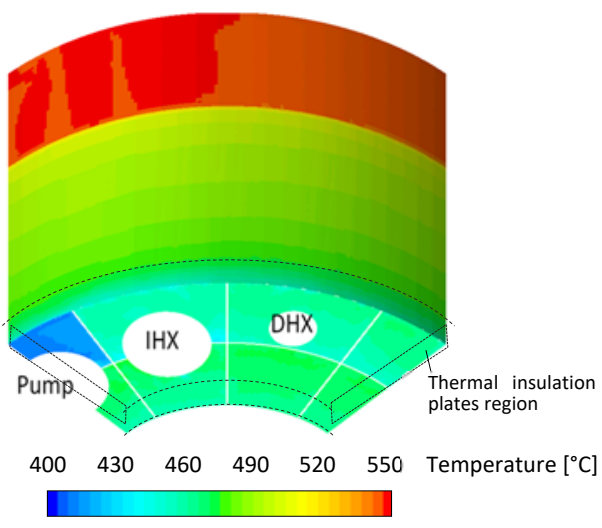

Fig. 9 Lower surface temperature of the plenum separator in the cold pool side.

plenum separator, cold, stagnant sodium around the pump observed in Fig. 9 spread through ribs, and the temperature distribution on the lower surface of the plenum separator was flattened (Fig. 13).

Figure 14 shows temperature distribution around the thermal insulation plates at the same position in Fig. 6 . The authors confirmed that the effect of the thermal insulation plates was improved. As a result, the temperature difference of the upper and lower surfaces of the thermal insulation plates became approx. $80^{\circ} \mathrm{C}$, which was $30^{\circ} \mathrm{C}$ larger than that without these measures. These measures are just conceptual examples to improve the effectiveness of thermal insulation plates at this moment. The measures will be reflected in the structural design in the detailed design stage.

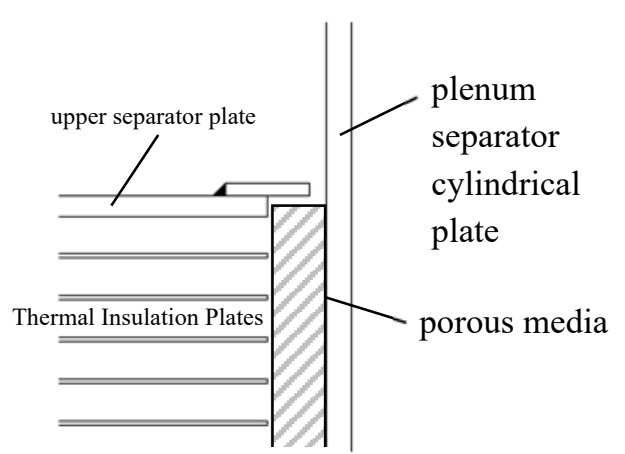

Fig. 10 Image of porous media simulated in gaps.

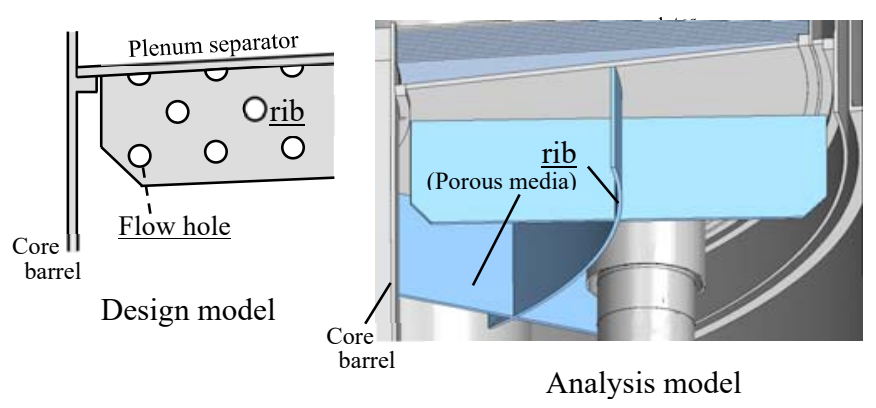

Fig. 11 Design and analysis models around rib. 


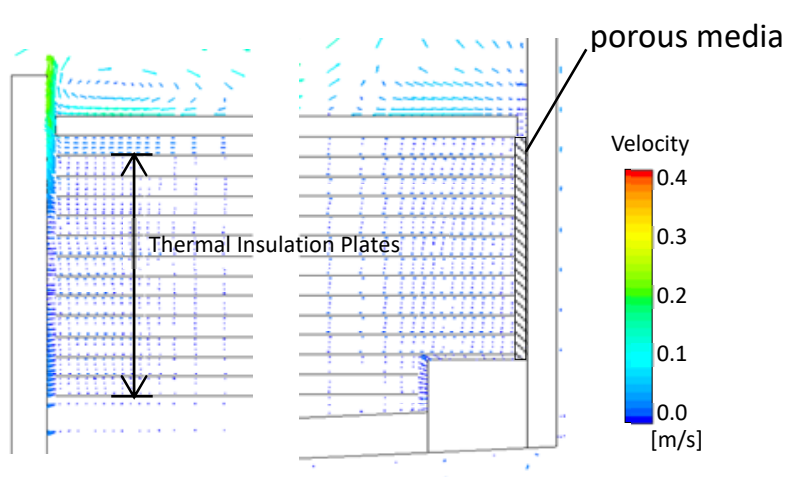

Fig. 12 Velocity distribution in the thermal insulation plates (countermeasure case).

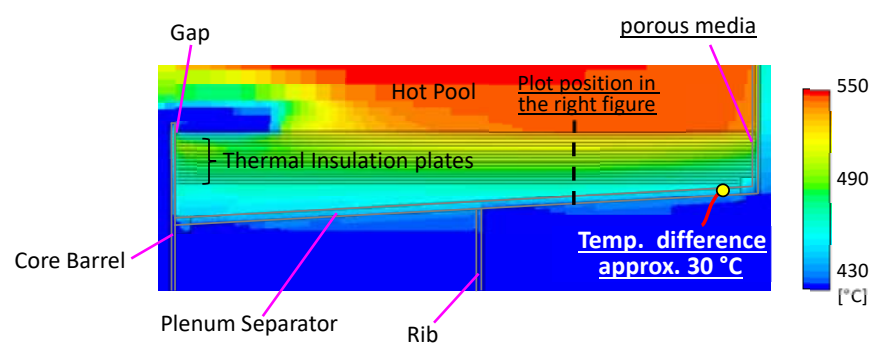

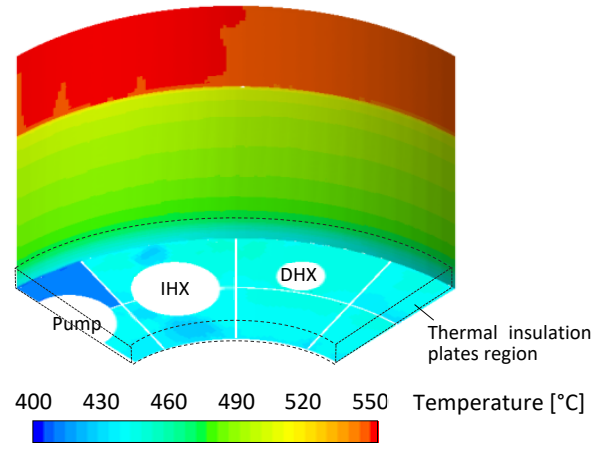

Fig. 13 Lower surface temperature of the plenum separator in the cold pool side (countermeasure case).

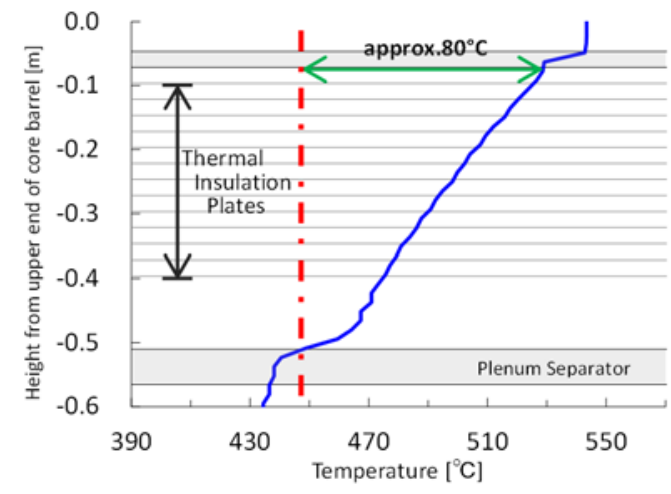

Fig. 14 Temperature distribution around the thermal insulation plates (countermeasure case).

\section{Study of safety design 4.1 Safety design concept}

The Generation IV International Forum (GIF) has been developing the SDC and SDGs for SFRs. Japan has played a leading role in the development based on the design technologies accumulated through various studies of the JSFR. This study has developed the safety design concept for the pool-type SFR based on the results of studies of the JSFR and GIF SDC and SDCs for SFRs considering the characteristics of pool-type SFRs. The design concept features six safety measures shown in Table 4. The authors focused on (i) Passive reactor shutdown measure and (iii) Measures to ensure decay heat removal because the difference between a loop-type SFR and a pool-type SFR significantly appears in their design conditions. As for (i), the SASS is applicable for the pool-type concept in the same manner as the JSFR. However, the cover gas pressure of a pool-type is slightly lower than that of a loop-type. Thus, the boiling point of sodium at the core outlet, where the SASS is installed, is lower. Therefore, the effectiveness of the SASS is quite important to prevent the coolant from boiling in an abnormal event without scram. Section 4.2 describes an applicability evaluation of the SASS to the pool-type SFR. Regarding (iii), since the internal volume of an RV of a pool-type is larger than that of a loop-type SFR in general, it is easier for a pool-type to install multiple heat exchangers as parts of the DHRS inside its RV. Section 4.3 describes the examination of the DHRS configuration, which considered sufficient utilization of natural circulation capability of sodium coolant, heat removal capacity of each cooling system, conformance with design requirements, and recommendations of SDC and SDG such as diversity and 
Kubo, Chikazawa, Ohshima, Uchita, Miyagawa, Eto, Suzuno, Matoba, Endo, Watanabe and Higurashi, Mechanical Engineering Journal, Vol.7, No.3 (2020)

redundancy of components (Kubo et al., 2015).

Table 4 Measures for safety design concept of the pool-type SFR.

\begin{tabular}{|c|c|}
\hline (i) Reactor shutdown measure & $\begin{array}{l}\text { - Two active reactor shutdown systems } \\
\text { - Passive reactor shutdown measure; the SASS using a Curie point electromagnet }\end{array}$ \\
\hline $\begin{array}{l}\text { (ii) Measures to achieve } \\
\text { in-vessel retention (IVR) } \\
\text { of damaged core }\end{array}$ & $\begin{array}{l}\text { Measures to mitigate the consequence of core damage resulting from anticipated } \\
\text { transients without scram (ATWS) (reduction of void reactivity to approx. } 6 \$ \text { or less, } \\
\text { provision of the fuel assembly with inner duct structure, transfer of re-molten fuels } \\
\text { from the control rod guide tube, and stable cooling and retention using a core } \\
\text { catcher) }\end{array}$ \\
\hline $\begin{array}{l}\text { (iii) Measures to ensure the } \\
\text { decay heat removal }\end{array}$ & $\begin{array}{l}\text { Prevention of complete loss of decay heat removal function; the DHRS } \\
\text { configuration considering the use of natural circulation capability, heat removal } \\
\text { capacity, and requirements of SDC and SDG } \\
\text { - Prevention of core uncovering and ensuring a primary coolant path for decay heat } \\
\text { removal; practical elimination of double leakage by securing high reliability of the } \\
\text { main vessel and the safety vessel }\end{array}$ \\
\hline $\begin{array}{l}\text { (iv) Formation of a } \\
\text { containment vessel (CV) } \\
\text { boundary }\end{array}$ & - Rectangular steel plate reinforced concrete CV (SCCV) \\
\hline $\begin{array}{l}\text { (v) Measures against sodium } \\
\text { leakage/combustion }\end{array}$ & $\begin{array}{l}\text { Double-wall structure for all sodium boundaries including secondary cooling } \\
\text { systems } \\
\text { - Compartmentation of the } \mathrm{CV} \text {, and inert atmosphere } \\
\text { - Transfer and storage of leaked sodium }\end{array}$ \\
\hline $\begin{array}{l}\text { (vi) Measures against } \\
\text { sodium-water reaction }\end{array}$ & $\begin{array}{l}\text { Water/steam leak detection system, pressure relief system, means for isolation of } \\
\text { sodium from steam/water and separation of hydrogen and other sodium-water } \\
\text { reaction products, and quick release/reduction of hydrogen }\end{array}$ \\
\hline
\end{tabular}

\subsection{Applicability evaluation of the SASS}

The SDC and SDG require that even if the function of the active reactor shutdown systems is lost, core damage should be prevented by using passive shutdown mechanism or inherent reactivity feedback, or their combination. The passive reactivity reduction mechanisms should

$>$ be activated and operated by directly responding to natural phenomena (such as increased coolant temperature or reduced coolant pressure) without any active signals, activation mechanisms or power source;

$>$ provide sufficient and irreversible negative reactivity within an allowable time to prevent core damage; and

$>$ cope with all types of ATWS (transient over power (TOP), loss of flow (LOF), and loss of heat sink (LOHS)).

The SASS is a passive control rod insertion mechanism using characteristics of electro-magnet that detach the control rods at a Curie point temperature (Fig. 15).

The cover gas pressure of the pool-type SFR is slightly lower than that of the JSFR, and therefore the boiling point of sodium is lower. The boiling point of sodium at the core outlet in the normal operation of the pool-type SFR is around $940^{\circ} \mathrm{C}$, whereas it is around $1,020^{\circ} \mathrm{C}$ in the JSFR. Therefore, the safety margin to coolant boiling in ATWS might be smaller than the JSFR (Saito et al., 2017).

A LOF type ATWS will cause the most severe temperature increase among other types of ATWS. To confirm the effectiveness of the SASS, this study conducted a transient analysis of a LOF type ATWS and evaluated the margin against coolant boiling by using a one-dimensional reactor system dynamics analysis code Super-COPD (Nakai et al., 1998, Yamada et al., 2009). The detachment temperature of the SASS was set at $660^{\circ} \mathrm{C}$, and the safety criterion of the maximum coolant temperature in the core was set at $940^{\circ} \mathrm{C}$ to prevent the coolant from boiling. 
Kubo, Chikazawa, Ohshima, Uchita, Miyagawa, Eto, Suzuno, Matoba, Endo, Watanabe and Higurashi, Mechanical Engineering Journal, Vol.7, No.3 (2020)

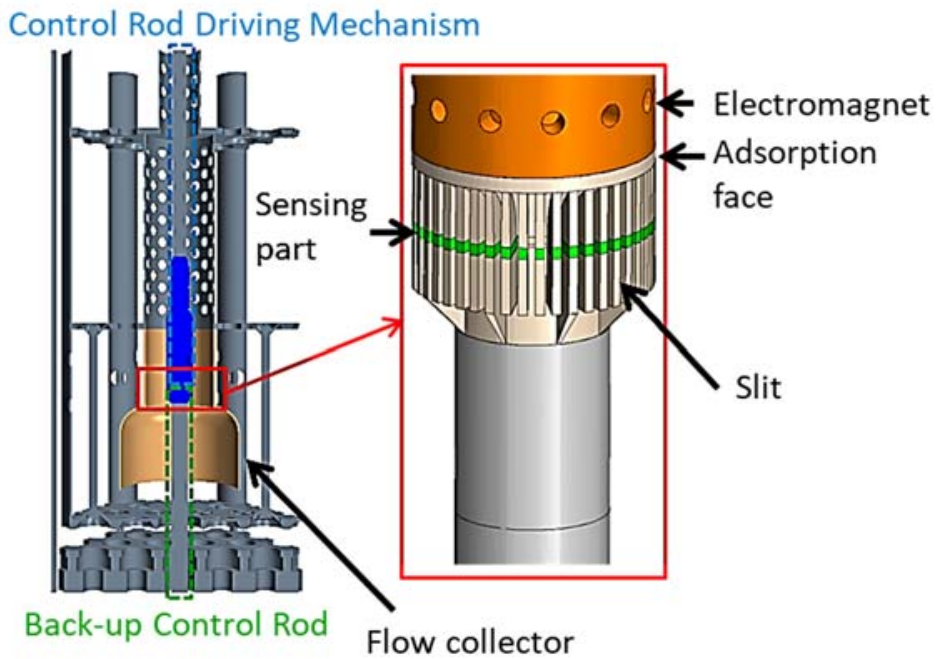

Fig. 15 Configuration of the SASS.

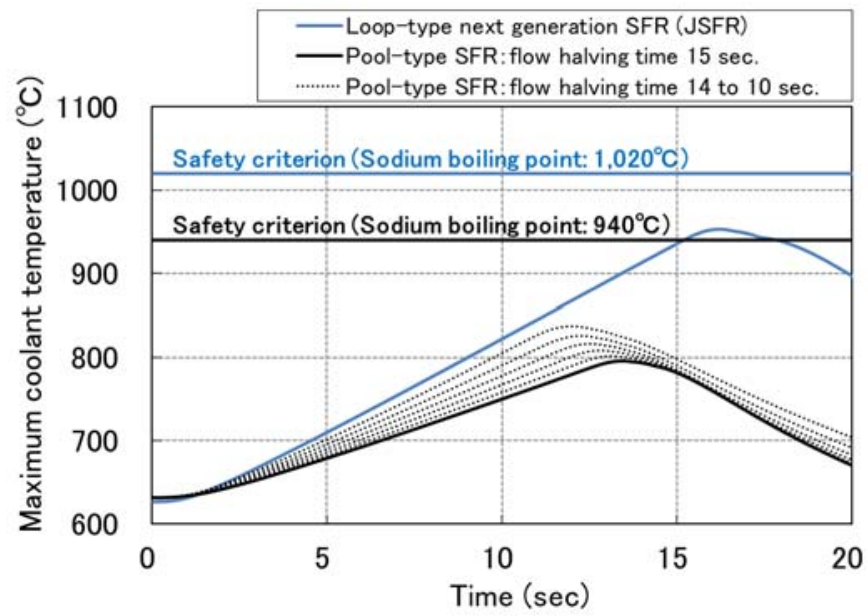

Fig. 16 Maximum coolant temp. in LOF type ATWS (initial power 100\%).

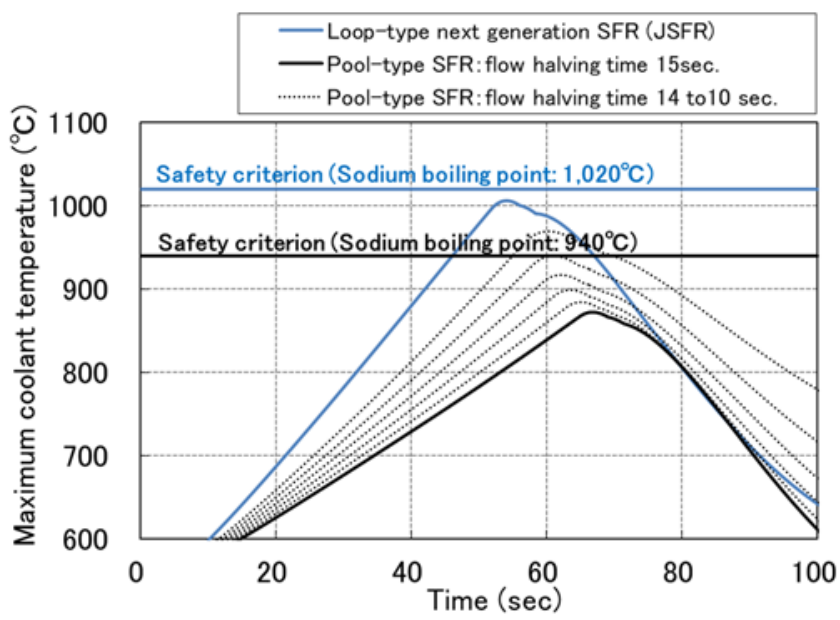

Fig. 17 Maximum coolant temp. in LOF type ATWS (initial power 30\%).

Figure 16 shows the analysis results of the maximum coolant temperature in a LOF type ATWS event under the initial condition of rated power (initial power 100\%), in which JSFR case (detachment temperature of the SASS: $650^{\circ} \mathrm{C}$, safety criterion: $1,020^{\circ} \mathrm{C}$ ) is also indicated for comparison. In this analysis, all primary pumps lost their power source and flow coast down started, and also two active shutdown systems were not activated. The nominal value of the flow halving time was 15 seconds. As shown in Fig. 16, the safety criterion was satisfied with sufficient margin, even in shorter flow halving time cases. In the JSFR case, its flow halving time was 9 seconds, and the coolant temperature rise was steeper than that of the pool-type SFR.

The authors also conducted an analysis of a LOF type ATWS event initiated under a 30\% partial power condition. In this case, the initial core outlet temperature was lower than that of $100 \%$ power condition, but the initial core flow rate was lower, and the response time of the SASS became longer. As shown in Fig. 17, the safety criterion was satisfied when the flow halving time was 15 seconds. However, if the flow halving time was shorter, the safety criterion could not be met.

The authors concluded that ensuring flow halving time is essential for the SASS under a LOF type ATWS to prevent the coolant from boiling. 
Kubo, Chikazawa, Ohshima, Uchita, Miyagawa, Eto, Suzuno, Matoba, Endo, Watanabe and Higurashi, Mechanical Engineering Journal, Vol.7, No.3 (2020)

\subsection{Decay heat removal systems}

The SDC and SDG require the following for DHRSs.

$>\quad$ The DHRS to deal with anticipated operational occurrences (AOOs) and design basis accidents (DBAs) should have redundancy and/or diversity in consideration of loss of off-site power and single failure criterion.

$>$ As measures to cope with design extension conditions (DECs), the capability of the DHRS should be extended, or alternative cooling measures should be provided.

$>$ Natural circulation capability should be incorporated while taking advantage of the characteristics of SFR.

$>$ The situations of complete loss of heat removal function that could lead to core damage and failure of the reactor coolant boundary should be practically eliminated.

Types of decay heat removal systems and their conceptual drawings are shown in Fig. 18. This study examined the configuration of DHRSs in the following steps. At first, the authors listed all conceivable concepts of cooling systems and evaluated their advantages and disadvantages from the viewpoints of natural circulation capability, heat removal capacity, amount of materials (cost) and applicability to the pool-type SFR (Table 5). Next, the authors examined combinations of these cooling systems that meet the requirements above.

\section{Selection of cooling systems}

Aiming at the utilization of natural circulation capability, the DRACS (immersed type), the DRACS (penetrated type) and the IRACS, which have favorable natural circulation heat removal capability, are picked out as conceivable concepts. Although the Primary Reactor Auxiliary Cooling System (PRACS) and the Reactor Auxiliary Cooling System (RACS) also have the natural circulation capability, they are not picked out since the structure of the IHX combined with the PRACS becomes complicated and the RV size becomes large, and the RACS, which takes primary sodium out of the RV, is not suitable for a pool-type SFR.

\section{DHRSs to cope with AOOs and DBAs}

Based on the deterministic analysis, the loss of function of two DHRSs is assumed for DHRSs to cope with AOOs and DBAs. This is due to the application of single failure criteria for one DHRS in case one DHRS failure assumed as an initiating event. A remained cooling system must ensure the required heat removal capacity. Also, in order to reduce the probability of common cause failure, it is preferable to apply different types of cooling systems as much as possible. Therefore, the DHRSs should be composed of more than three independent systems. And these systems should be diversified at least into two groups.

Through the analysis, the DRACS (immersed type) and the IRACS are selected for the DHRS to cope with AOOs and DBAs. Regarding the DRACS, different types of DRACSs (penetrated type) could be the candidate, but the DRACS (immersed type) is selected. From the viewpoint of enhancing diversity, the IRACS is selected as another type of cooling system.

The number of systems is as follows. As for the DRACS (immersed type), its DHX is installed in the hot pool, and core cooling relies significantly on the inter wrapper flow, as shown in Fig. 19(a). On the other hand, core cooling by the IRACS relies on the main flow path, i.e., core inlet to outlet, hot pool, IHX and cold pool, as shown in Fig. 19 (b). The inter-wrapper flow caused by the DRACS (immersed type) may impede the main flow if it has a larger heat removal capacity. Therefore, only one DRACS (immersed type) is assigned. On the other hand, as for the IRACS, four cooling systems are assigned conforming to the number of the secondary cooling system. The IRACS has an advantage that the RV size is not affected by increasing the number of IRACSs.

For DHRSs to cope with AOOs and DBAs, natural circulation capability is utilized in the primary, the secondary and the air-cooling systems.

\section{DHRS to cope with DECs}

The SDC and SDG recommend providing additional cooling measures against DECs, which is independent from DHRSs to cope with AOOs and DBAs, and to ensure the required heat removal capacity by at least one system on the assumption that the functions of DHRSs to cope with AOOs and DBAs are lost completely. In response to this recommendation, one DRACS (penetrated type) is assigned as an additional cooling measure. In the DRACS 
(penetrated type), its DHX penetrates from the hot pool to the cold pool, and core cooling is performed by the main flow path, as shown in Fig. 19 (b). However, part of the flow to the IHX is bypassed to the DRACS (penetrated type) during normal operation. Therefore, some countermeasures with R\&D, such as installing a shutter at the inlet of the DHX, are necessary to restrain the bypass flow during normal operation. Since the DRACS (penetrated type) has the necessity of R\&D for the shutter, it is assigned as alternative cooling measures instead of DHRSs to cope with AOOs and DBAs.

For the DHRS to cope with DECs, natural circulation capability is utilized in the primary cooling system, but forced circulation is used for the secondary cooling system and the air-cooling system from the viewpoint of diversity.

\section{Equipment configuration of decay heat removal system}

Figure 20 depicts the selected candidate of the DHRS configuration using the DRACS (immersed type) and the IRACS to cope with AOOs and DBAs, and the DRACS (penetrated type) as an alternative cooling measure to cope with DECs. Both the DRACS and the IRACS have a simple structure. This configuration has sufficient heat removal capacity and natural circulation capability as well as independence and diversity to cope with severe internal and external hazards and meets SDC and SDG requirements and recommendations. Physical separation is taken into account to prevent the simultaneous loss of their function.

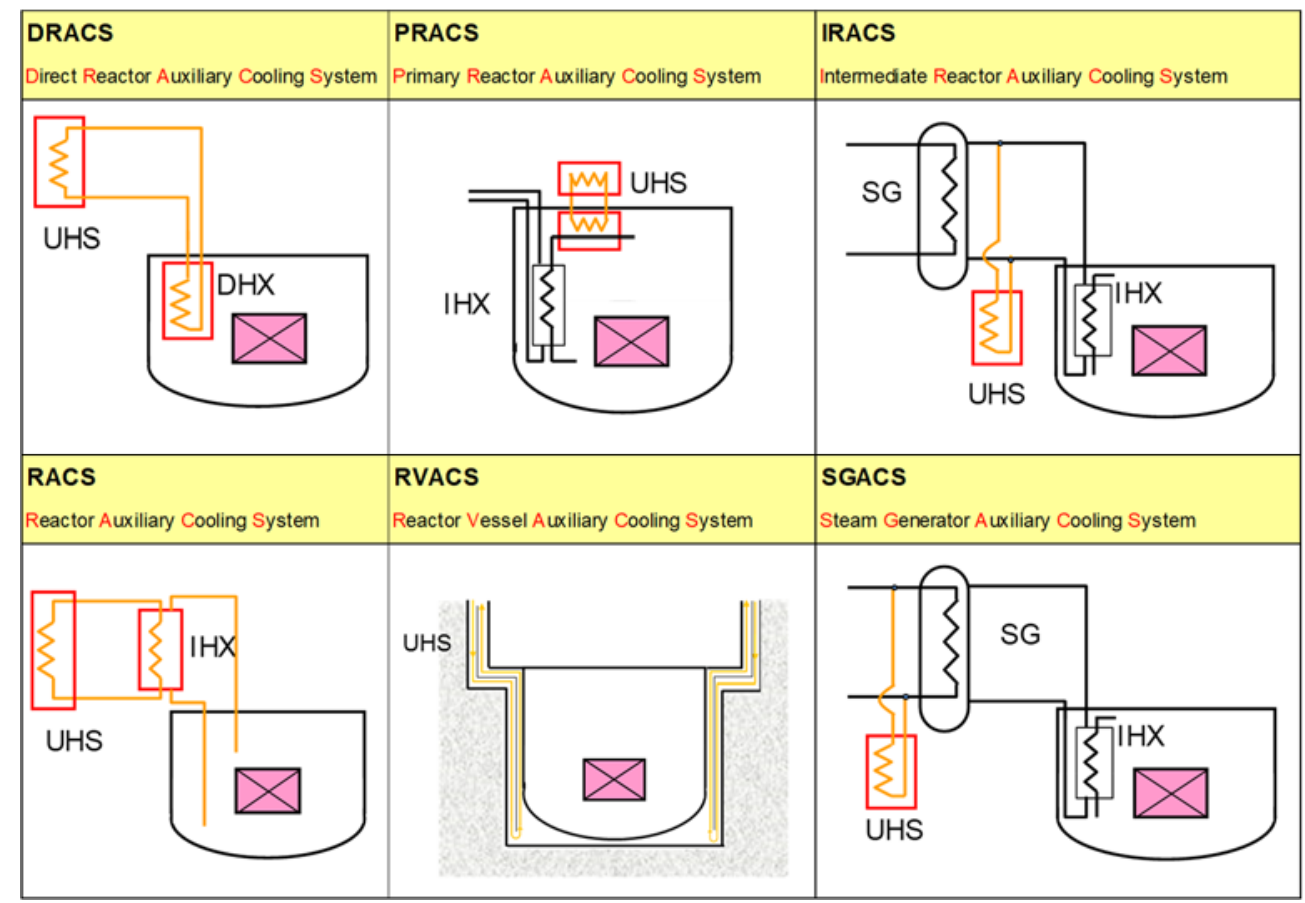

DHX: heat exchanger of DRACS, IHX: intermediate heat exchanger, PHX: heat exchanger of PRACS, SG: steam generator, UHS: ultimate heat sink, (Orange and red lines show decay heat removal systems.)

DRACS is classified into two types. The first one is an immersed type whose DHX is installed in the hot pool. The second one is a penetrated type whose DHX penetrates from the hot pool to the cold pool.

Fig. 18 Types of decay heat removal systems. 
Kubo, Chikazawa, Ohshima, Uchita, Miyagawa, Eto, Suzuno, Matoba, Endo, Watanabe and Higurashi, Mechanical Engineering Journal, Vol.7, No.3 (2020)

Table 5 The evaluation of each cooling system.

\begin{tabular}{|c|c|c|c|}
\hline \multirow{2}{*}{$\begin{array}{l}\text { Cooling system } \\
\text { concept }\end{array}$} & \multicolumn{2}{|c|}{ Advantage } & \multirow{2}{*}{ Disadvantage } \\
\hline & Common items & Special notes & \\
\hline $\begin{array}{c}\text { DRACS } \\
\text { (immersed type) }\end{array}$ & \multirow{5}{*}{$\begin{array}{l}\text { - Enough heat removal } \\
\text { capacity } \\
\text { - Natural circulation } \\
\text { capability } \\
\text { - } \quad \begin{array}{l}\text { Simple air cooling } \\
\text { system }\end{array}\end{array}$} & $\begin{array}{l}\text { - Less restriction of heat } \\
\text { exchanger location }\end{array}$ & $\begin{array}{l}\text { Validation of inter wrapper flow } \\
\text { core cooling is necessary. }\end{array}$ \\
\hline $\begin{array}{c}\text { DRACS } \\
\text { (penetrated type) }\end{array}$ & & \multirow{3}{*}{$\begin{array}{l}\text { - Simple and high core } \\
\text { cooling natural } \\
\text { circulation }\end{array}$} & $\begin{array}{l}\text { - R\&D for shutter of primary } \\
\text { sodium inlet is necessary. }\end{array}$ \\
\hline PRACS & & & $\begin{array}{l}\text { Diameter increase of RV due to } \\
\text { complicated structure around } \\
\text { IHX }\end{array}$ \\
\hline IRACS & & & $\begin{array}{l}\text { Loss of function caused by } \\
\text { secondary heat transport system } \\
\text { failure }\end{array}$ \\
\hline RACS & & $\begin{array}{l}\text { - Small impact on the } \\
\text { design of RV }\end{array}$ & $\begin{array}{l}\text { - Presence of primary sodium } \\
\text { circuit out of RV } \\
\text { - Slight pressurization of cover gas } \\
\text { is necessary. }\end{array}$ \\
\hline RVACS & \multicolumn{2}{|c|}{ - Less susceptible to in-vessel events } & $\begin{array}{l}\text { - Difficulty in securing heat } \\
\text { removal capacity }\end{array}$ \\
\hline SGACS & \multicolumn{2}{|c|}{$\begin{array}{l}\text { Enough heat removal capacity when using } \\
\text { water/steam cooling equipment }\end{array}$} & $\begin{array}{l}\text { Loss of function caused by } \\
\text { secondary heat transport system } \\
\text { failure }\end{array}$ \\
\hline
\end{tabular}

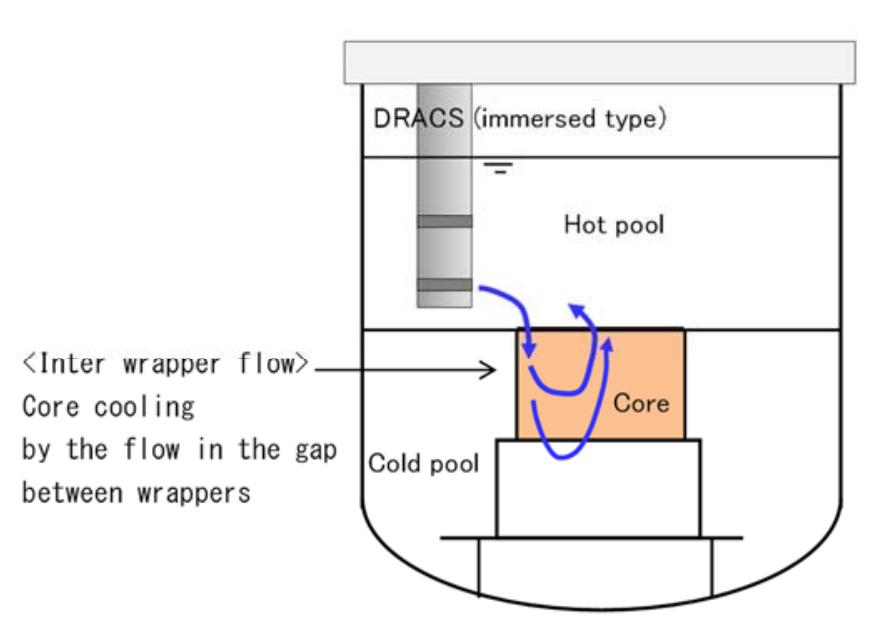

(a) Complex and limited core cooling occurs by the operation of DRACS (immersed type)

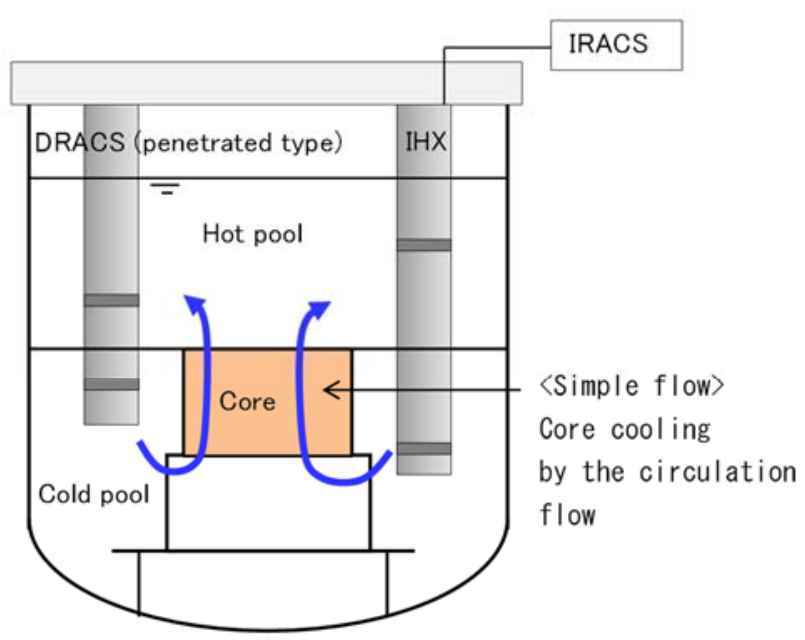

(b) Simple and high core cooling occurs by the operation of IRACS and DRACS (penetrated type)

Fig. 19 Primary flow patterns assumed in the natural circulation situation. 


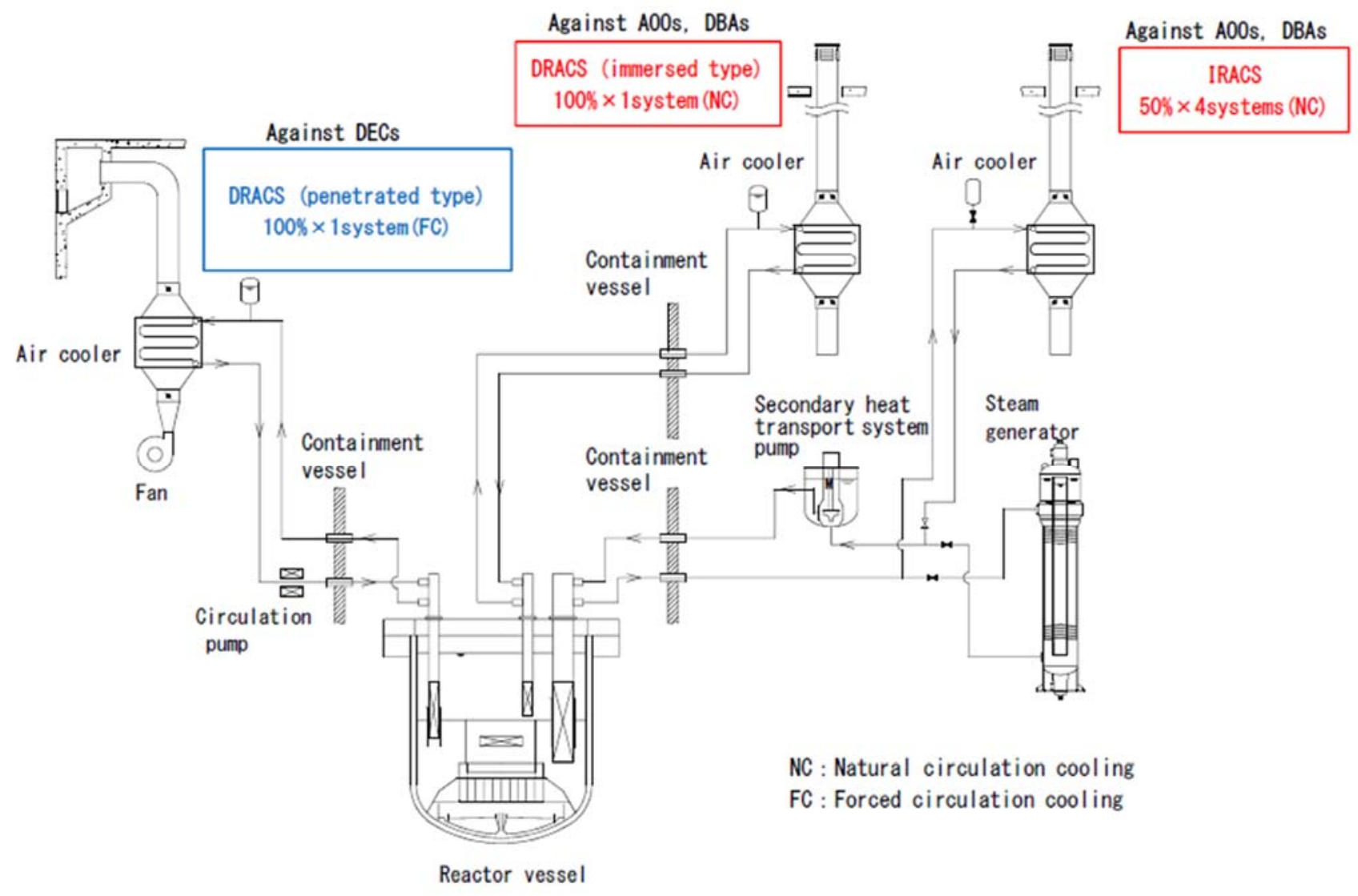

Fig. 20 The candidate of the DHRS structure.

\section{Conclusions}

The authors have examined the design concept of the 1,500 MWt (650 MWe) class pool-type SFR by applying the design technology obtained from the design of advanced loop-type SFR, named JSFR, equipped with safety measures that reflect results from the FS and FaCT, improved maintainability and repairability, and lessons learned from the Fukushima Daiichi Nuclear Power Plants accident.

The design concepts of the RV and its internal structures have been investigated whether they could withstand severe seismic conditions in Japan and thermal loads by applying a horizontal seismic isolation system on the base of its reactor building. Although the thickness of the cylindrical part of the RV should be increased 50 to $55 \mathrm{~mm}$ depending on the seismic conditions, the design concept to cope with the seismic loads was thought up featuring enhanced RV support structure, enhanced conical-shaped core support structure, a thickened knuckle part of the RV, and a flat plenum separator with the ribs. If the three-dimensional seismic isolation system is adopted, the required thickness of the RV will be reduced to approx. $40 \mathrm{~mm}$, even for a potential larger power plant (1,500 MWe). This study has conducted the analysis of three-dimensional steady-state thermal hydraulic in the RV to confirm the resistance of the flat-shaped single plate plenum separator with thermal insulation plates against a thermal load at a rated operating condition. A temperature difference of the upper and lower surfaces of the plenum separator became approx. $30^{\circ} \mathrm{C}$, which was $80^{\circ} \mathrm{C}$ lower than that of the conical-shaped structure without the thermal insulation plates.

This study has developed the safety design concept for pool-type SFR based on the results of studies of the JSFR and GIF SDC and SDC for SFRs considering the characteristics of pool-type SFRs. The authors conducted transient analyses of a LOF type ATWS events under $100 \%$ and $30 \%$ initial power conditions to evaluate the feasibility of the SASS. With the design concept, the safety criterion of the maximum coolant temperature $940^{\circ} \mathrm{C}$ was not exceeded both in $100 \%$ and $30 \%$ initial power cases with the flow halving time 15 seconds. The DHRS configuration developed in 
this study was also investigated considering sufficient utilization of natural circulation capability of sodium coolant, heat removal capacity of each cooling system, conformance with design requirements, and recommendations of SDC and SDG such as diversity and redundancy of components. The selected candidate of the DHRS configuration consists of the DRACS (immersed type) and IRACSs to cope with AOOs and DBAs, and the DRACS (penetrated type) as an alternative cooling measure to cope with DECs.

\section{Nomenclature}

$\begin{array}{ll}\text { AOO } & \text { Anticipated Operational Occurrence } \\ \text { ATWS } & \text { Anticipated Transients Without Scram } \\ \text { CDA } & \text { Core Disruptive Accident } \\ \text { DBA } & \text { Design Basis Accident } \\ \text { DEC } & \text { Design Extension Condition } \\ \text { DHRS } & \text { Decay Heat Removal System } \\ \text { DHX } & \text { Decay Heat Exchanger } \\ \text { DRACS } & \text { Direct Reactor Auxiliary Cooling System } \\ \text { IHX } & \text { Intermediate Heat Exchanger } \\ \text { IRACS } & \text { Intermediate Reactor Auxiliary Cooling System } \\ \text { IVR } & \text { In-vessel Retention } \\ \text { LOF } & \text { Loss of Flow } \\ \text { LOHS } & \text { Loss of Heat Sink } \\ \text { PRACS } & \text { Primary Reactor Auxiliary Cooling System } \\ \text { RACS } & \text { Reactor Auxiliary Cooling System } \\ \text { RV } & \text { Reactor Vessel } \\ \text { SASS } & \text { Self Actuated Shutdown System } \\ \text { SCCV } & \text { Steel plate reinforced Concrete CV } \\ \text { SDC } & \text { Safety Design Criteria } \\ \text { SDG } & \text { Safety Design Guidelines } \\ \text { SFR } & \text { Sodium-cooled Fast Reactor } \\ \text { TOP } & \text { Transient Over Power }\end{array}$

\section{Acknowledgments}

The present study is the result of "Technical development program on a fast reactor international cooperation, etc." entrusted to the Japan Atomic Energy Agency (JAEA) by the Ministry of Economy, Trade and Industry (METI).

\section{References}

Fukasawa, T., et al., Research and Development of Rubber Bearings for Sodium-Cooled Fast Reactor: Ultimate Properties of Half-Scale Thick Rubber Bearings Based on Breaking Tests Journal of Pressure Vessel Technology, Volume 140, Issue 1 (2018), research-article.

Fukasawa, T., et al., Research and Development of Three Dimensional Seismic Isolation System for Sodium-Cooled Fast Reactor (Paert4) Proposal of Optimal Combination Method for Disc Spring Units and Newly Friction for Sliding Elements, Proceedings of ASME Pressure Vessels and Piping Conference (2019), PVP2019- 93480.

GIF SDC-TF, Safety Design Criteria for Generation IV Sodium-cooled Fast Reactor System (Rev.1) (2016).

GIF SDC-TF, Safety Design Guidelines on Safety Approach and Design Conditions for Generation IV Sodium-cooled Fast Reactor Systems (2016).

Hayafune, H., et al., Conceptual Design Study for the Demonstration Reactor of JSFR (1) Current Status of JSFR Development, Proceedings of ICONE19 (2011), ICONE19-44140.

IAEA, IAEA-TECDOC-1531, Fast Reactor Database 2006 Update (2006).

Isono, K., et al., Studies on Maintainability and Repairability for Japan Sodium-cooled Fast Reactor (JSFR), Proceedings of ICONE22 (2014), ICONE22-30175.

Kamide, H., et al., JSFR Design Progress related to Development of Safety Design Criteria for Generation IV 
Kubo, Chikazawa, Ohshima, Uchita, Miyagawa, Eto, Suzuno, Matoba, Endo, Watanabe and Higurashi, Mechanical Engineering Journal, Vol.7, No.3 (2020)

Sodium-cooled Fast Reactors (1) Overview, Proceedings of ICONE23 (2015), ICONE23-1666.

Kotake, S., et al., Feasibility Study on Commercialized Fast Reactor Cycle Systems Current Status of the FR System Design, Proceedings of GLOBAL 2005 (2005), No. 435.

Kubo, S., et al., JSFR Design Progress related to Development of Safety Design Criteria for Generation IV Sodium-cooled Fast Reactors (2) Progress of Safety Design, Proceedings of ICONE23 (2015), ICONE23-1748.

Matsuura, S., et al., 1993, Formulae for Evaluating Buckling Strength of FBR Main Vessels under Earthquake Loading, JSME International Journal, Vol.36, No.3 (1993), pp.485-492.

Miyagawa, T., et al., Research and Development of Three Dimensional Seismic Isolation System Utilized Coned-Disc-Springs with Rubber Bearings, Proceedings of ASME Pressure Vessels and Piping Conference (2017), PVP2017- 65549.

Nakai, S., Iwasaki, T., Shimakawa, Y., Tanji, M., Development of Module Integrated Plant Dynamics Analysis Code -Development of Super-COPD Code- (1988), PNC Technical review No.68-3 (in Japanese).

Saito, H., et al., Safety Evaluation of Self Actuated Shutdown System for Gen-IV SFR, Proceedings of ICAPP 2017 (2017), 17439.

Uchita, M., et al., Seismic evaluation for a large-sized reactor vessel targeting SFRs in Japan, Proceedings of ICAPP2018 (2018), 23797.

Varaine, F., et al., The Significant Collaboration of Japan and France on the Design of ASTRID Sodium Fast Reactor since 2014, GIF Symposium - Paris (France) (2018).

Yamada, F., Ohira, H., Okusa, K., Miyakawa, A., Validation of plant dynamics analysis code Super-COPD by MONJU startup tests, International Conference on Fast Reactors and Related Fuel Cycles (FR09) (2009), Paper No. IAEA-CN-176-06-39P. 